\title{
CRÍTICA DA RECEPÇÃO CRÍTICA DE JOÃO PAULO BORGES COELHO NO BRASIL
}

CRITICS OF THE CRITICAL RECEPTION OF JOÃO PAULO BORGES COELHO IN BRAZIL CRÍTICA DE LA RECEPCIÓN CRÍTICA DE JOÃO PAULO BORGES COELHO EN BRASIL

\section{RESUMO:}

O ensaio discute a recepção crítica da obra literária de João Paulo Borges Coelho no Brasil. O material de análise é a produção de artigos acadêmicos em publicações brasileiras. O ensaio está organizado em quatro partes. Na primeira, apresento a noção de obra literária como conquista da produção de Borges Coelho. Na segunda, discuto algumas questões da recepção crítica no Brasil da literatura moçambicana, propondo um diferente enquadramento a partir da noção de literatura mundial. Na terceira, analiso características da recepção crítica de Borges Coelho no Brasil. Na quarta, proponho novas frentes de investigação.

PALAVRAS-CHAVE: Recepção crítica, literatura mundial, literatura moçambicana, João Paulo Borges Coelho.

\section{ABSTRACT:}

The essay discusses the critical reception of the literary work of João Paulo Borges Coelho in Brazil. The material analysed is the production of academic articles in Brazilian publications. The essay is organized in four parts. In the first one, I present the notion of literary work as the conquest of the production of Borges Coelho. In the second part, I discuss some issues of 
the critical reception in Brazil of Mozambican literature, proposing a different framework from the notion of world literature. In the third, I analyze characteristics of the critical reception of Borges Coelho in Brazil. Finally, I propose new research fronts.

KEY-WORDS: Critical reception, world literature, Mozambican literature, João Paulo Borges Coelho.

\section{RESUMEN:}

El ensayo discute la recepción crítica de la obra literaria de João Paulo Borges Coelho en Brasil. El material de análisis es la producción de artículos académicos en publicaciones brasileñas. El ensayo está organizado en cuatro partes. En la primera, presento la noción de obra literaria como conquista de la producción de Borges Coelho. En la segunda, discuto algunas cuestiones de la recepción crítica en Brasil de la literatura mozambiqueña, proponiendo un encuadramiento diferente a partir de la noción de literatura mundial. En la tercera, analizo características de la recepción crítica de Borges Coelho en Brasil. En la cuarta, propongo nuevos frentes de investigación.

PALABRAS CLAVE: Recepción crítica, literatura mundial, literatura mozambiqueña, João Paulo Borges Coelho.

\section{Introdução}

Este ensaio pretende discutir a recepção crítica realizada no Brasil à obra de João Paulo Borges Coelho. Para tanto, dividi o texto em quatro momentos. No primeiro, faço considerações sobre a contemporaneidade da produção do autor, pensando-a enquanto obra, isto é, como conjunto já sedimentado de produções, dotado de densa complexidade em relação ao mapeamento literário de Moçambique em termos geográficos e históricos. No segundo momento, levanto algumas questões a respeito da recepção crítica no Brasil da literatura moçambicana. Para tal discussão, oriento-me por uma breve revisão da noção de literatura mundial a partir da compreensão das especificidades das relações no eixo Sul-Sul. Num terceiro tempo, trato especificamente da recepção crítica no Brasil ao trabalho literário de Borges Coelho. Adotando perspectiva comparatista, e partindo de um enquadramento da discussão na sociologia literária, busco ali desenvolver relações com a recepção crítica à obra de Mia Couto. Por fim, no quarto momento, sugiro encaminhamentos que considero necessários, ausentes ou pouco adensados na já significativa recepção crítica do autor no Brasil. Destaco, entre outras considerações, a necessidade de se repensar um eixo já aparentemente bastante explorado, o das relações entre o Borges Coelho literato e o Borges Coelho historiador. 
Quero esclarecer os limites deste trabalho: não se trata de estudo exaustivo, mas da abordagem de algumas categorias interpretativas referentes à leitura crítica da obra ficcional do autor no Brasil. Eliminei as entrevistas e os trabalhos de mais fôlego, como dissertações e teses. Assim, muitos estudos de críticos brasileiros publicados no estrangeiro também não serão aqui abordados. O objeto deste trabalho se restringiu basicamente a artigos em revistas acadêmicas brasileiras. Nisso se poderá analisar também o fôlego e a especificidade da recepção acadêmica nacional a autores africanos de língua portuguesa, verificando o teor das "estruturas de sentimento africanizantes" (SOARES, 2011) presentes atualmente no Brasil.

É preciso começar afirmando que a poética de um autor também é construída na sua recepção. Parto da concepção mais básica da estética da recepção que é a da atualização de uma obra por sua leitura. A leitura crítica está situada no presente e parte sempre de um histórico de leituras. A crítica literária se faz a partir de conjugações de horizontes de expectativas, como propunha Hans R. Jauss (1994). Mesmo que se recuse a poética da fruição ingênua do belo em nome do desvelamento do procedimento (como propuseram os formalistas russos), a restrição à textualidade parece-me uma perspectiva do vácuo, não remetendo a obra à relação inevitável com a história das produções e leituras e ao entorno das obras menores e secundárias (as que a antecedem, as que com ela convivem e as que a sucedem). Parto de uma história de leituras, e nisso encaminho a minha leitura. A perspectiva aqui é de atualização dos diversos horizontes de expectativas que conformam a percepção crítica da obra de Borges Coelho. Ocorre que isso não invalida a percepção de como a imanência da obra contraria/confirma as expectativas quanto ao romance africano/moçambicano/pós-colonial. Não se perde de vista a poética, portanto.

\section{A obra de João Paulo Borges Coelho}

Destacarei, a seguir, três componentes centrais para a constituição de uma obra em Borges Coelho: o do escritor, o do mercado e o da crítica. O primeiro é interno, diz respeito à própria consciência textual presente na literatura recente do autor, ciente já do seu percurso e aparentemente repensando sua produção. Entre outras coisas, desfazendo-se da representação nacional (ainda que a contrapelo) em nome de uma ecoliteratura (Água), da metaficção histórica (Rainhas da noite) e da autoficção (Ponta Gea). O segundo componente a constituir uma obra é a dimensão mercadológica (e aí pesam também os mais recentes lançamentos dos livros em formato digital). O terceiro componente é o da crítica, na qual se operam já panoramas de mais longo alcance, inclusive com a primeira tese de doutoramento inteiramente dedicada ao autor a ser defendida em instituição brasileira ${ }^{2}$.

\footnotetext{
2 Cf. BRAUN, Ana Beatriz Matte. O "outro" moçambicano: expressões da moçambicanidade em João Paulo Borges Coelho. Trata-se da primeira tese em instituição brasileira, tendo sido defendida em 2016. A primeira tese, de instituição não-brasileira, defendida em 2011, é de Nazir A. Can (Universitat Autònoma de Barcelona).
} 
É possível dizer que Borges Coelho, publicando literatura desde 2003, tenha levado apenas uma década para constituir o que chamamos de uma obra. Uma primeira etapa de uma obra que ainda promete muito, diga-se. Situo propositadamente em 2013 a constituição de tal obra, pois ali, no meu entender, ocorre uma virada de representação com a publicação de Rainhas da noite. Com este romance, o autor assenta uma obra no sentido em que faz da reflexão alegórica sobre sua literatura e sua própria condição de escritor moçambicano um dos elementos estruturais mais destacados do livro. Ali, o narrador passa a ser figurado como historiador, e os modos de configuração do passado, as estratégias de memória veiculadas nos livros anteriores, são postos em consideração. Uma dupla consideração, portanto, de narrador e de formas de memória, que passam a ser explicitamente pensados diante dos leitores. O movimento irônico ${ }^{3}$, desse dobrar-se sobre si mesmo e sobre o discurso, parece vir confirmado mais recentemente com Ponta Gea (2017), no qual de fato adentramos à ficcionalização do eu.

Pode-se pensar na noção de obra literária em Borges Coelho também a partir de duas instâncias que a situam mais ou menos no mesmo período. De um lado, no plano editorial, temos finalmente a veiculação de alguns livros do escritor no formato digital. Ao lado do premiado $O$ olho de Hertzog, também Rainhas da noite, Água e Ponta Gea (os livros mais recentes) estão disponíveis em e-book, o que certamente resultará num maior alcance de público, em particular no Brasil, objeto de nossa discussão.

Noutro plano, temos a dimensão crítica, com iniciativas que em muito contribuem para a constatação de que há no escritor uma obra a ser pensada já na sua integridade e heterogeneidade, isto é, já se faz possível um balanço. O momento mais recente é o deste dossiê, consagrando um autor moçambicano numa revista acadêmica brasileira. Quanto a dossiês temáticos referentes a outros escritores moçambicanos, há apenas dois: José Craveirinha (na revista "Via Atlântica", em 2006) e Mia Couto (na revista "Nau Literária", em 2011). De fato, nos últimos vinte anos, aproximadamente, houve um crescimento considerável de publicações e dossiês destinados às literaturas produzidas em países africanos de língua oficial portuguesa ${ }^{4}$. A quase totalidade dos dossiês, porém, não especifica algum(a) escritor(a). O dossiê da revista "Nau Literária" (2011, p.1) sobre Mia Couto, no entanto, não resultou de uma intenção crítica especificamente voltada à sua obra (como é o caso deste dedicado a Borges Coelho), mas mais propriamente de uma certa inflação de materiais, como se pode ler na "Apresentação" do volume:

3 Penso em "ironia" aqui no sentido desenvolvido por Arthur Nestrovski (1996), em Ironias da Modernidade. Irônica é a condição moderna da literatura a partir de Shakespeare, significando um movimento no qual a linguagem se suspende e se põe em questão.

4 A título de exemplo, tome-se a revista "Via Atlântica", publicada pela USP. À parte os dossiês mais genéricos, temos: dossiê "África" (n. 3, 1999), dossiê "José Craveirinha" (n. 5, 2002), dossiê "Cabo Verde: texto e contexto" (n. 10, 2006), dossiê "Moçambique - história, literatura e relações culturais" (n. 16, 2009), dossiê "Goa, literatura e cultura" (n. 19, 2011) e dossiê “Goa, literatura e cultura - 2" (n. 30, 2016). 
Como antecipamos no último número, esta edição da Revista Nau Literária contempla textos que atenderam nossa chamada do início do ano para o tema de Literaturas Africanas em Língua Portuguesa. Dada a expressiva e qualificada resposta que obtivemos, optamos por realizar duas edições e, desse modo, publicar todos os textos aprovados em nosso processo editorial. Considerando ainda que vários desses artigos abordavam a obra do moçambicano Mia Couto, dedicamos-lhe o Dossiê do presente número.

Como se percebe, sem a intenção crítica dos organizadores em torno à obra de Mia Couto, a presença de um dossiê em seu nome acaba num lugar conceitual impreciso, entre a redundância e a onipresença. Também é curioso que até o momento não tenhamos nas publicações brasileiras dossiês dedicados a nomes importantes como José Eduardo Agualusa, Noémia de Sousa, Ruy Duarte de Carvalho, Ungulani Ba Ka Khosa etc. Percebe-se, pois, um lugar especial dedicado a Borges Coelho na crítica literária brasileira, ainda que suas obras não circulem no mercado editorial nacional.

Dois outros momentos críticos, ainda, justificam que pensemos na produção literária do autor como uma obra já sedimentada. Tratam-se de eventos de balanço, destinados ao recenseamento da melhor produção crítica sobre o autor. O primeiro deles foi o evento acadêmico "Cartógrafo de memórias: a poética de João Paulo Borges Coelho", ocorrido na Universidade de Lisboa, em julho de 2017. Foram dois dias com a presença da maioria dos principais estudiosos da literatura do autor (e com a presença do próprio, lançando o livro Ponta Gea). No mesmo evento internacional ocorreu o lançamento do livro Visitas a João Paulo Borges Coelho (KHAN et al., 2017). O volume marca o outro momento crítico da recepção ao autor moçambicano, na medida em que não apenas reúne novos estudos sobre diferentes momentos de sua carreira literária, como também traz um longo artigo de Nazir Can (apud KHAN et al., 2017), "Crônica de outras visitas: A recepção crítica da obra literária de João Paulo Borges Coelho", no qual o princípio didático é o predominante na recensão operada. Há o duplo objetivo de síntese (mapeando a crítica) e sistematização:

Assim, de modo a mapear o território interpretativo da obra de JPBC da forma mais exaustiva possível, incluirei recensões, ensaios, teses de mestrado e de doutoramento, textos publicados na blogosfera ou em jornais, bem como apresentações oficiais dos livros do autor a que tive acesso. Este levantamento, meramente descritivo, visa, portanto, sintetizar e sistematizar as principais incursões feitas sobre a prosa de JPBC de modo a se constituir como ferramenta útil para futuros estudos sobre a obra literária do autor. (CAN apud KHAN et al., 2017, p. 13)

Destaco a centralidade desse primeiro artigo do livro (e para efeitos pedagógicos é perfeito que esteja no início do livro), pois é dali que se estabelece o positivo confronto entre o que se fez e o que no livro se faz. Can não faz julgamentos de valor, esforçando-se em apontar os objetivos de cada texto e a manipulação conceitual e bibliográfica empreendida. O estudioso 
observa a pluralidade de discussões sobre o autor que conduzem a outro patamar a questão literária em Moçambique, destacando o aumento da investigação crítica sobre Borges Coelho.

\section{Algumas questões sobre a recepção crítica no Brasil da literatura moçambicana}

Evocando o fato de que a literatura de Borges Coelho se esmera na explicitação crítica de que não há estabilidade nas representações identitárias, pensar na literatura africana é necessariamente um esforço dialógico em relação, por exemplo, à sua percepção fora da África. Literatura moçambicana, nesse sentido, seria um termo relacional, a ser pensada também no escopo de sua recepção externa. Se há uma história nessa relação, há também a dinâmica política. Nesse sentido, acho produtivo contrapor tais aspectos à noção de literatura mundial (ou, na origem em Johann W. von Goethe, de Weltliteratur).

Pretendo expor, a seguir, alguns posicionamentos críticos a respeito desse enquadramento Sul-Sul na discussão da literatura mundial. Antes, quero destacar que a apreensão mais complexa de tal enquadramento deveria partir já diretamente da emergência do pós-colonialismo como crítica do universal imperialista. Em paralelo, tem-se a emergência do multiculturalismo, no qual a diversidade passa a ser pensada como patrimônio e projeto a ser operado pelas políticas de tradução e pelos sistemas literários. O mercado monopolista global da literatura, nesse ponto, deveria ser contraposto à situação do Brasil no eixo mais específico das relações Sul-Sul, o que nos permitiria pensar, por fim, na condição da literatura africana lusófona na sua recepção brasileira (em termos relacionais e dinâmicos). Tal percurso não é objeto deste texto, e me concentrarei apenas nos aspectos mais imediatos da questão.

"É através de Moçambique que vejo o mundo" é o título de uma entrevista de Borges Coelho, publicada em $2006^{5}$. A intenção deste ensaio é a inversão de tal perspectiva: é através do mundo que a literatura moçambicana de Borges Coelho é vista. Muito desse mundo receptivo está no Brasil, justamente onde o autor não está publicado. Um dos problemas mais nítidos da recepção do escritor é o da falta de produções acadêmicas próprias de Moçambique. Se nomes como Fátima Mendonça e Francisco Noa nunca descuraram da atenção ao autor, a própria ausência institucional de pesquisas de pós-graduação em literatura no país foi responsável pela ausência de horizontalização das investigações. Nesse ponto, corre-se sempre o risco da persistência da "biblioteca colonial”. É o que aponta Noa: "cada vez mais a consagração do escritor africano e do moçambicano, em particular, depende perversamente dos areópagos literários do exterior" (NOA, 2006, p. 269).

Penso que Borges Coelho se constitui, talvez justamente pela ausência no mercado edi-

\footnotetext{
5 Entrevista a João Paulo Borges Coelho. Disponível em http://macua.blogs.com/moambique_para_ todos/2006/04/joo_paulo_borge.html. Acesso em 30 jan. 2018.
} 
torial brasileiro, num caso paradigmático para se entender a recepção às literaturas periféricas como um novo movimento que possibilita a reconfiguração da noção de literatura mundial. Observando a bibliografia estudada por Can (apud KHAN et al., 2017), o que se tem é um mínimo acompanhamento nacional moçambicano à obra do ficcionista. Dos 101 textos consultados por Can, apenas 8 foram publicados a partir de Moçambique, a maioria artigos de jornal. Nesse ponto, configura-se o paradoxo de um autor de circulação internacional (já traduzido ao italiano e com traduções em curso ao inglês e ao espanhol), ganhador de um importante prêmio no mercado lusófono (LeYa), e que, mesmo não editado no Brasil, tem no país talvez seu principal polo receptor e consagrador.

Considero a discussão de Pascale Casanova (2002) como uma das mais adequadas para a discussão da literatura mundial, na medida principalmente em que articula a literatura ao par língua-política. A autora postula que, no quadro do "romance pós-colonial”, haveria um aspecto menos previsto: ele confirma a vitória linguística da nação colonizadora, mostrando como sua língua/literatura pode ser revivida/rearticulada em outro contexto. Daí a importância de noções como francofonia ou lusofonia. Os escritores excentrados assinalariam a vitória da língua colonizadora. Nessa ambiguidade, tudo que se confedera (como no prêmio LeYa, obtido por Borges Coelho) é parte do poder de irradiação da língua, mas em geral escrito contra a própria metrópole. É um atestado de tolerância (e de superioridade) da metrópole aceitar tais discursos (enquanto discursos e não enquanto práticas, note-se). No caso da lusofonia, teríamos duas forças de impacto dominante, Portugal e o Brasil. Essa dupla fonte de força fez com que escritores africanos tenham podido se apoiar na literatura brasileira como contestação à literatura portuguesa, por exemplo.

A discussão dessa dimensão nos conduz para a revisão da própria noção de literatura mundial. Para Hugo Achugar (2006), as mais recentes concepções de literatura mundial (como as de Franco Moretti ou de Pascale Casanova), apesar de suas diferenças, unificam-se na medida em que tomam o estético a partir de uma possibilidade universalista. Achugar sugere, a contrapelo, que a universalidade não pode ser pensada fora de suas comunidades interpretativas. Isto é, o universal (o autor cita a noção a partir de Judith Butler) só pode ser pensado a partir de sua linguagem cultural: o universal comporta valores que obscurecem fissuras e desigualdades. $\mathrm{Ou}$ seja, é preciso se precaver em relação às apropriações apriorísticas que obscureçam aquelas fissuras do universal. Eduardo C. Dias (2014) sugere dois temas centrais para a presente discussão quanto à abordagem externa das literaturas africanas: o apriorismo que conjuga singularidade e unicidade dos africanos e do continente africano e a descontextualização da história nas suas homogeneidades e heterogeneidades.

Para a discussão de tais valores, por fim, gostaria agora de contrapor duas percepções distintas sobre o fenômeno. As posições de Lorenzo Macagno e de Alfredo C. Melo partem de enquadramentos distintos, mas não é isso que orienta suas conclusões e sim uma diferenciada 
leitura da relação das estruturas africanizantes no Brasil.

Para o antropólogo Macagno (2014), nos últimos anos a África se teria tornado uma marca no Brasil, um significante sujeito a diversas apropriações, submetidas ao jogo político. Uma das principais entradas institucionais no Brasil foram os departamentos de Letras, que trazem constantemente autores PALOP. Para o estudioso, ambiguidades e ameaças naciocêntricas rondam este retorno tardio à África.

Macagno faz uso da recepção a Borges Coelho para exemplificar a distância que há em relação à recepção brasileira de produções acadêmicas provenientes da África. Como questão de fundo, nota-se uma crítica a tal apropriação literária, vista como romântica e à caça do exotismo. Ocorre que Macagno considera, ao final do trecho abaixo, ser este também um problema do mercado editorial, o que não é, como sabemos, uma questão que diga respeito à literatura de Borges Coelho, tão ausente aqui como as produções historiográficas ou sociológicas dos países africanos:

A título de exemplo, um dos sintomas desse "orientalismo" está no crescente reconhecimento da obra literária de João Paulo Borges Coelho, historiador moçambicano. Trata-se de um historiador, cujos trabalhos acadêmicos abordam questões referentes à guerra de libertação nacional, à desmobilização pós-guerra civil e à violência. Mas não são seus trabalhos de historiador que chegam até nós, mas seus recentes romances. Por que o João Paulo Borges Coelho escritor resulta mais "interessante" que o João Paulo Borges Coelho historiador? Ou melhor, por que África literária, por assim dizer, resulta mais "vendável" do que a África sociológica ou antropológica? [...] Mas o primado de um olhar estetizante, orientalista e emocional à África, ofusca mais do que esclarece: ele é mais uma fonte de compatibilidades equívocas do que de afinidades eletivas. Quem sabe uma mudança de direção decisiva poderá começar, quando o imenso campo editorial no Brasil comece a prestar atenção não apenas nos escritores africanos, mas, também, nos antropólogos, sociólogos e historiadores desse continente. (MACAGNO, 2014, p. 132)

Por outro lado, e pensando na superação de um único paradigma analítico na literatura comparada brasileira, Melo sugere uma entrada a partir da dinâmica Sul-Sul, pensando-a de modo crítico. O investigador confere especial atenção às relações entre Brasil e África lusófona:

Ora, já está mais do que na hora de tirar as consequências do status de média potência mundial desfrutado pelo Brasil, no qual estabelece relações de poder com outros países a partir de outros arranjos. O caso da África lusófona parece ser o mais ilustrativo. Faz-se necessário discutir com mais vagar essa posição ambivalente da cultura brasileira no mundo. (MELO, 2013, p. 20)

Haveria, segundo o autor, uma ambivalência na posição brasileira, que além da solidariedade periférica cultivaria também uma postura neocolonizadora. Melo vai pensar especificamente no impacto da literatura brasileira sobre a África lusófona, mas sua questão pode ser 
direcionada também para a dinâmica da recepção, na medida em que cabe ao público brasileiro (no caso específico de Mia Couto) e à crítica brasileira (no caso específico de Borges Coelho), parte considerável das atenções dedicadas aos escritores da lusofonia africana. Melo apresenta, pois, um programa de investigações sob critério crítico: "Essa relação Sul-Sul seria uma relação baseada na emulação ou na colaboração? Que tipo de dinâmica de poder seria criada entre esses países?" (2013, p. 24)

Quero sugerir, pois, que se passe a analisar a obra de Borges Coelho também a partir das questões da literatura mundial (e nesse enquadramento Sul-Sul), pensando como autores mundiais não apenas o que o eurocentrismo e o mercado multicultural consideram, mas principalmente os autores cuja circulação e recepção se fazem fora do espectro nacional. É preciso considerar o moçambicano Borges Coelho como autor mundial, pois assim é sua recepção.

\section{João Paulo Borges Coelho lido pela crítica no Brasil}

Onde está a recepção crítica à literatura de Borges Coelho? Sem erro, pode-se dizer que em grande parte esteja no Brasil. Em Moçambique, ainda que autor premiado (Prêmio José Craveirinha 2006, com As visitas do Dr. Valdez, e Prêmio BCI 2017, com Ponta Gea), ainda há pouca absorção crítica de sua literatura. No levantamento realizado por Can, o estudioso destaca o aumento da investigação crítica sobre o autor: "Dos cerca de 100 documentos aqui recompilados, a maioria é publicada a partir de 2010. [...] muitas dessas miradas vêm do Brasil, país onde os livros de JPBC não foram ainda editados." (CAN apud KHAN et al., 2017, p. 43). Naquela centena de textos, cerca de $15 \%$ apenas provinham de veículos moçambicanos (na maioria, textos de divulgação em sítios ou revistas). Em comparação, cerca de $35 \%$ dos estudos provinham de veículos brasileiros (os demais, principalmente de Portugal, mas também dos Estados Unidos e de outros países). O próprio volume Visitas a João Paulo Borges Coelho expressa tal defasagem, pois a única presença de investigação moçambicana ali presente (entre 14 ensaios) é o curtíssimo texto (ainda que preciso) - quatro páginas - de Fátima Mendonça (“Ovídio e Kafka nas margens do Lúrio”).

No Brasil, mesmo entre o público acadêmico, a primeira pergunta usualmente feita para quem diz trabalhar com literatura moçambicana ainda é: “com Mia Couto?” Borges Coelho é um nome raro no Brasil. Isso se manifesta em sua inexistência editorial/comercial no país. Poetas (como José Craveirinha, Luís Patraquim e mesmo os mais jovens) já tiveram coletâneas no Brasil, bem como prosadores como Paulina Chiziane e, obviamente, Mia Couto. Além das coleções por editoras universitárias, desde 2014 a editora Kapulana vem lançando livros de países africanos de língua portuguesa oficial. De outro lado, uma simples consulta digital ao maior 
portal de livros usados no Brasil, a Estante Virtual, mostra 1508 volumes à venda de Mia Couto 6 e absolutamente nenhum de Borges Coelho. O autor só é acessível através de edições importadas, cópias piratas ou e-books, tendo uma recepção ainda bastante escassa e dificultada, não só para um leitorado leigo como para os próprios pesquisadores acadêmicos. Enquanto isso, só em 2016 houve o lançamento ou reedição de 16 títulos de Mia Couto pela editora Companhia das Letras.

Opõem-se, assim, dois modelos de recepção, sendo o de Borges Coelho até agora exclusivamente o da crítica especializada. Na grande mídia brasileira, há apenas uma menção na Folha de S. Paulo (a respeito do prêmio LeYa) e uma entrevista de canal de tevê fechado ${ }^{7}$. Diferentes instâncias consagradoras, portanto. Em termos de mercado uma questão é se há espaço no mercado editorial brasileiro para dois autores moçambicanos brancos (questão complexa e que aponta para os dilemas editoriais da literatura mundial à caça de exotismos). Difícil elaborar prognósticos, mas a divulgação digital de livros de Borges Coelho pode estar a reverter tal anonimato. Uma breve investigação estatística pode nos situar melhor neste momento de balanço.

Observe-se, por exemplo, o Banco de Teses e Dissertações da Capes $^{8}$. Há 229 pesquisas concluídas sobre Mia Couto, sendo 55 teses e 174 dissertações. É um autor fartamente estudado nos cursos de graduação (inclusive por começar a publicar muito mais cedo que Borges Coelho). Borges Coelho aparece com 6 menções no mesmo portal da Capes (menos de 3\% em relação ao colega). Inverte-se, porém, a hierarquia acadêmica, pois são 4 teses e 2 dissertações. Foram 2 trabalhos em 2013, 1 em 2015 e 3 em 2016.

De outro lado, temos já no Brasil mais de uma dezena de revistas dedicadas à literatura africana de língua portuguesa. Tomemos algumas delas. Na revista "Mulemba", a busca por Mia Couto tem 31 textos, enquanto Borges Coelho aparece com 6. Na "Via Atlântica"10, são 22 referências a Borges Coelho e 76 referências sobre Mia Couto. Na revista "Navegações"11, constam 16 menções a Mia Couto e 4 a Borges Coelho. Na revista "Nau Literária"12, são 16 títulos sobre Mia Couto e nenhum sobre Borges Coelho. A pergunta a se fazer é sobre qual seria o rendimento dessa produção massiva concentrada em Mia Couto. Estudando a recepção crítica à literatura de Mia Couto, Ana C. da Silva chega a uma desoladora constatação:

O levantamento dessas informações fez-se necessário quando, no decorrer

\footnotetext{
6 Pesquisa realizada em 30-01-2018, em https://www.estantevirtual.com.br/ busca?utf $8=\% \mathrm{E} 2 \% 9 \mathrm{C} \% 93 \&$ type $=\mathrm{q} \&$ new $=\& \mathrm{q}=$ mia + couto

7 http://globotv.globo.com/canal-futura/umas-palavras/v/umas-palavras-ep-110-paulo-borgescoelho/1352269/.

8 Pesquisa realizada em 30-01-2018, em http: / / catalogodeteses.capes.gov.br/catalogo-teses/\#!/.

9 Pesquisa realizada em 30-01-2018, em https://revistas.ufrj.br/index.php/mulemba

10 Pesquisa realizada em 30-01-2018, em https://www.revistas.usp.br/viaatlantica

11 Pesquisa realizada em 30-01-2018, em http://revistaseletronicas.pucrs.br/ojs/index.php/navegacoes

12 Pesquisa realizada em 30-01-2018, em http://seer.ufrgs.br/NauLiteraria
} 
da leitura dos trabalhos que reunimos, percebemos uma insistência/repetição de temas, abordados, por vezes, com o mesmo referencial teórico, como é o caso da recriação linguística operada por Mia Couto, da aproximação entre a sua escrita e a oralidade moçambicana, do chamado realismo maravilhoso ou fantástico presente nos enredos etc. Tais investigações, refeitas em vários trabalhos, fizeram-nos supor que os pesquisadores brasileiros da obra de Mia Couto não liam os trabalhos uns dos outros (2010, p. 77).

Na recepção crítica a Borges Coelho, pode-se dizer que a situação é a inversa. A distribuição crítica do escritor parece obedecer a um funcionamento artesanal, o que a fez coisa de iniciados. Livros, referências, reflexões, são passados como de mão em mão. A beleza e o alto valor dessa condição - um fogo que ninguém pode deixar que se extinga, a passagem do bastão, a passagem da tocha olímpica -, porém, pode esconder ou impedir certos desenvolvimentos críticos que articulem o interesse por uma obra de fato tão rica e original para outras searas de intérpretes e leitores. Por outro lado, é evidente a diferença na relação entre mercado editorial e recepção crítica. Se no mercado brasileiro, Borges Coelho se faz ausente e Mia Couto é um best-seller, na recepção crítica a situação estatística até que não é de todo desigual. O fato de haver mais teses que dissertações sobre Borges Coelho já nos diz um pouco das exigências que sua literatura impõe. Ressalte-se, pois, que toda a recepção crítica ao ficcionista se fez à margem do mercado editorial, exatamente o contrário daquela voltada a Mia Couto, de certo modo pelo mercado induzida. Note-se, por outro lado, que muitos dos hoje estudiosos de Borges Coelho iniciaram pela pesquisa em Mia Couto.

Com relação aos artigos brasileiros sobre Borges Coelho, discutirei a seguir aspectos negativos (contumazes na crítica mais iniciante) e discussões de grande potencial heurístico (na crítica mais experiente no autor). Nas abordagens mais solitárias e iniciantes, a discussão em geral aborda temáticas que entrelaçam história e literatura, muitas vezes reduzindo à reconstrução histórica a obra ficcional do autor, no contexto das abordagens pós-coloniais. Há ainda poucas linhas de pensamento desenvolvidas, pouca discussão cruzada entre a própria recepção crítica e mesmo uma redução da obra do autor a alguns livros mais analisados (como As duas sombras do rio e As visitas do dr. Valdez). Os contos, as novelas e mesmo as bandas desenhadas são quase exceções nas análises críticas da academia brasileira. $\mathrm{O}$ virtual desconhecimento público de Borges Coelho (o "outro moçambicano" como no título da tese de Ana B. Braun, de 2016) resulta igualmente em textos que necessariamente reapresentam o autor ao leitor. Além disso, as entrevistas do escritor são muitas vezes utilizadas acriticamente e sem mediações como endosso da análise crítica. A questão do recurso às entrevistas me parece fundamental nessa discussão. Faz-se frequentemente a associação das leituras com a própria condição identitária do autor. Este é um dos maiores riscos das análises, essa recorrência ao próprio autor, suas entrevistas e biografia. Ainda há pouco questionamento das opções estéticas e ideológicas das construções literárias de Borges Coelho. Isto é, assume-se, usualmente, seu protocolo de leitura, 
o que é um problema crítico. Penso que seria muito mais proveitoso uma leitura dialogante com tais protocolos. Também se deveria considerar que são protocolos sempre abertos, sempre advogando pela liberdade da própria literariedade diante das analogias e da história autocentrada dos discursos oficiais de poder.

O dado biográfico (por exemplo, o ser historiador) é inevitável e reiterativo. Nos leitores mais ingênuos, o início dos artigos é a aproximação padrão dos textos sobre o autor: biografia, história e literatura, sempre a partir de entrevistas ou depoimentos do próprio. Logo, sempre se parte de um lugar ancorado, seguro. Além de tudo, usualmente se repete que seus livros se passam em Moçambique, fazem mapeamento e articulam presente e passado num jogo entre memória oficial e memórias particulares. Há uma espécie de precariedade, de informação de release. Que consequências isso tem para a crítica? Primeiro se legitima, depois se restringe a leitura pela biografia quanto a duas questões: nacionalidade (identidade) e profissão.

Dito isto, façamos um excurso arqueológico: como Borges Coelho chega às publicações acadêmicas no Brasil? Salvo engano, a primeira menção a seu nome surge num artigo de antropologia, de 2005, de autoria do português João P. Cabral. E o que nos diz Cabral? O artigo trata das "crises de fraternidade" nas relações entre literatura e etnicidade na produção artística moçambicana. $\mathrm{O}$ antropólogo certamente lê com equívocos a presença da questão em As duas sombras do rio. $\mathrm{O}$ argumento central é que os novos nacionalismos trouxeram a quebra das solidariedades cotidianas. Ora, a obra literária de Borges Coelho foi justamente nesse sentido, resgatando as memórias individuais e embaralhando as polaridades identitárias. Para Cabral, ao contrário, Borges Coelho teria insistido no binarismo, demonizando as forças militares.

Pode-se dizer que, após a crítica pioneira de Cabral, tenham se constituído duas categorias de leitores de Borges Coelho no Brasil, os alegóricos, às voltas com a representação do nacional pelo literário e os que partem de questões teóricas da literatura cuja base não é o mimetismo representacional. Chamo-os de teóricos. Os primeiros em geral são os críticos retratados acima, pesquisadores avulsos que abordam apenas uma obra e que não têm mais de um texto sobre o autor: também podem ser vistos como leitores mais ingênuos. Os teóricos são os autores que manipulam muitas obras.

Aijaz Ahmad (2002) identifica em Fredric Jameson a matriz analítica da alegoria nacional como típica das literaturas não centrais. Segundo Ahmad, Jameson teria distinguido uma lógica cultural na produção cultural dos países centrais de uma ênfase nas alegorias nacionais na produção dos países periféricos. O problema de tal vinculação, segundo Ahmad, é que o nacionalismo é um conceito ideologicamente polissêmico. Devo dizer que as leituras alegorizantes são também as mais essencializantes, não especificando Moçambique no continente africano. São propostas análises que tomam de modo apriorístico o literário, por exemplo, sugerindo a unicidade de uma subjetividade africana ou enquadrando a literatura de Borges Coelho nas discus- 
sões de oralidade. Há, enfim, uma atitude tateante, sem muitos gestos ousados, justamente em medida de uma espécie de crítica no escuro, na qual nem as obras do autor como um todo são conhecidas. Faz-se a resenha de um livro sem saber direito como são os outros, algo inevitável por não haver circulação editorial da obra no país.

Já nas leituras que se distanciam da alegorização, as instâncias teóricas tenderiam ao propriamente literário. São diversas as questões teóricas abordadas, sendo que uma das mais necessárias ainda é a discussão das implicações epistemológicas das relações entre história e literatura. Entram em jogo nessas análises, por exemplo, discussões sobre a especificidade do pós-colonialismo moçambicano (KHAN, 2008). Talvez o primeiro texto a abordar diretamente a negação da alegoria tenha sido o de Can, intitulado "Para além da história" (2009). Analisando Campo de trânsito, Can aponta aporias do pós-colonialismo, propondo uma leitura de certo modo desterritorializada.

A perspectiva teórica é contra-alegórica. Assim, ao enfatizar as memórias individuais e as personagens de identidade bifronte, o ficcionista estaria a contrariar a versão oficial homogeneizante da alegoria nacional, num procedimento contra-alegórico. Quanto à relação com a história, Carmen T. Secco (2009) é das poucas a tratar do tema em termos conceituais. Para ela, o procedimento do autor em As duas sombras do rio tem homologia com a História Nova, abrindo-se às subjetividades cotidianas.

Destaco, por fim, uma análise que pode ampliar o campo de debate. A discussão de Mendonça, publicada em revista brasileira, postula uma espécie de recepção ocidental a exigir o hibridismo como nova forma de essencialização:

Estas novas relações, predominantemente económicas, acabam por reintroduzir pela sua acção (editoras, cooperação institucional etc.), muitos dos tópicos caros à justificação da empresa colonial, nomeadamente o dos traços deixados pela sua acção e que se integrariam sem sobressalto nas culturas daí resultantes, o que me parece estar a dois passos do actual conceito de hibridismo (2011, p. 144).

Considero o artigo de Mendonça como um dos mais ricos em consequências, na medida mesmo em que sai da esfera da lusofonia e faz comparativismo em termos continentais. De resto, considero-o como um dos únicos textos que de fato faz comparativismo, isto é, que busca obter resultados para além da análise em separado de cada autor.

\section{A abertura de novas frentes de investigação}

Há dois eixos que considero serem extremamente necessários para o aprofundamento das discussões sobre a literatura de Borges Coelho. São eixos que compreendem estratégias de aná- 
lise interna. Estou pensando, pois, na poética do ficcionista. São duas discussões: a do narrador, ainda pouco presente, e a da relação entre ficção e história, já tão presente.

A discussão do narrador e dos modos de representação é proposta aqui como maneira de se alcançar um acompanhamento que nos permita visualizar mudanças num autor que, como propus acima, tem já uma obra. Tem-se a impressão, muitas vezes, lendo a crítica, de que não aconteceram mudanças na ficção do autor. O narrador é ponto central nessa discussão, pois em geral as discussões tomam a representação por objeto e não aquela figura literária que a empreende. O narrador raramente aparece situado nas análises. Poucas análises arriscam definir a posição de tal narrador como central para o entendimento da matéria ficcional. A discussão de Braun figura como um exemplo do que proponho:

Os narradores não são etnográficos, nem pós-modernos; são tradicionais, contam a partir da experiência e da observação distanciada. Mas são autoetnográficos, incorporando, criticamente, a visão do colonizador acerca dos colonizados, em especial, nessas narrativas, por meio do discurso do burlesco. Parece, em resumo, que, em um momento em que as ciências se voltam para a subjetividade, João Paulo Borges Coelho evoca a voz da autoridade do narrador/ historiador para contar histórias sobre o encontro de culturas (2012, p. 118).

Arif Dirlik (2006) comenta que a teoria pós-colonial sofreu uma inflexão a partir da década de 1990. Para o autor, há uma virada do pós-colonial em direção às condições híbridas e flexíveis, recusando identidades solidificadas, tudo fruto de um stress com a questão espacial pós-colonial. Considero a obra de Borges Coelho como um rico material para contemplar a tensão entre tal pulverização e os apegos regionais, comunitários ou ancestrais das personagens, isto é, aquela tensão com a questão espacial e de identidade. A pulverização das identidades, se é uma conquista moderna, individualizando e dando voz às subjetividades, é ao mesmo tempo a desconfiança com as estratégias normativas da homogeneidade das comunidades imaginadas pelo poder. Porém, tal democratização do plano diegético (todos terem direito a voz) deve ser pensada à luz daquela centralização heterodiegética operada pelos narradores. O problema, talvez, seja a da inevitável consequência de tal discussão, qual seja a consideração da posição social desses narradores. A função de tais narradores, se por um lado é a de evitar os exotismos com que se constrói comercialmente a recepção das produções simbólicas das periferias mundiais, é, por outro lado, demarcar uma diferença com a matéria. É um narrador da onisciência, mas principalmente do arbítrio. Assim, um estudo de grande proveito seria o de se pensar em "quem são" os narradores de Borges Coelho em relação à matéria diegética. Deve-se considerar que aquele imperativo da diversidade faz uma crítica mais atenta à homogeneização operada pela política pós-independência. Nesse ponto, seria útil pensar em como (talvez) difira a representação do escritor de períodos coloniais e pós-coloniais.

Outro eixo é o da relação entre ficção e história. Aparentemente seria um eixo já bastante 
visitado e investigado, mas creio haver na maioria das análises um problema de ordem epistemológica. Usualmente se discute a literatura de Borges Coelho à luz das relações entre ficção e história, mas raramente se discute de que "história" se está falando nessas relações. Não existe praticamente na crítica aqui analisada o uso da produção acadêmica historiográfica de Borges Coelho como material que possa friccionar as análises literárias e introduzir de modo mais produtivo a intersecção disciplinar. Nas publicações historiográficas, note-se, o autor é apresentado como historiador. Não há a menção usual da dupla atuação, como sói acontecer nas análises literárias. Então, se partimos comumente da interpretação de um literato que é também historiador, é preciso que consigamos ir mais fundo nos problemas daí decorrentes. Por exemplo, se Borges Coelho é historiador, isso significa que nas suas peças ficcionais a dimensão histórica é um a priori inquestionável? Em que medida a crítica se vê induzida aí a aceitar de pronto as narrativas como alegoria histórica?

\section{Conclusões}

Num artigo ainda mal lido, na minha opinião, intitulado "A pesquisa em torno das Literaturas Africanas de Língua Portuguesa: pontos para um balanço”, Rita Chaves (2010) faz uma autocrítica dos estudos brasileiros sobre literaturas africanas lusófonas, sugerindo alguns pontos de questionamento. O primeiro é o da contextualização histórica e cultural dos sistemas literários. O segundo ponto é o da necessidade interdisciplinar (avançar mais na Antropologia e na História, sugere a autora). Um terceiro ponto seria a atenção às pesquisas feitas pelos próprios compatriotas dos escritores, recebendo também a voz local crítica. Outro ponto é ter consciência de nossa condição: aquela literatura não é a nossa, e a língua portuguesa pode criar uma falsa aproximação. Por fim, a dimensão da oralidade, ainda mal resolvida na crítica brasileira.

Penso que, com exceção do último ponto, todos sejam extremamente válidos para a consideração da literatura de Borges Coelho e que tenham sido de algum modo abordados neste ensaio. Quero deixá-los também como sugestões para futuras leituras, como as outras que propus acima. O enquadramento Sul-Sul na literatura mundial, a visão relacional entre Moçambique e Brasil, as discussões sobre o narrador nas peças literárias e uma melhor consideração epistemológica das relações entre ficção e história são algumas dessas possibilidades. Tal generosidade (de Chaves) e as propostas que aqui apresentei, perceba-se, só são possíveis pelo apreço ao esforço literário de Borges Coelho e, principalmente, pelo apreço que a crítica brasileira (e mundial) a ele tem concedido.

\section{REFERÊNCIAS:}

ACHUGAR, Hugo. Planetas sem boca: escritos efêmeros sobre arte, cultura e literatura. 
Belo Horizonte: Editora UFMG, 2006.

AHMAD, Aijaz. Linhagens do presente. São Paulo: Boitempo Editorial, 2002.

BRAUN, Ana Beatriz Matte. O "outro" moçambicano: expressões da moçambicanidade em João Paulo Borges Coelho. Tese de doutorado. Disponível em: https://dspace.c3sl.ufpr.br/handle/1884/45394. Acesso em 30 jan. 2018.

. Sobre a relação entre literatura e etnografia em João Paulo Borges Coelho. In: Revista Mulemba, v.4, n.6, 2012.

CABRAL, João de Pina. Crises de fraternidade: Literatura e etnicidade no Moçambique PósColonial. In: Horizontes Antropológicos, Porto Alegre, ano 11, n. 24, p. 229-253, jul./dez. 2005.

CAN, Nazir. Para além da história: Campo de Trânsito de João Paulo Borges Coelho. In: Via Atlântica, n. 16, dez, 2009.

CASANOVA, Pascale. A república mundial das letras. São Paulo: Estação Liberdade, 2002.

CHAVES, Rita. A pesquisa em torno das Literaturas Africanas de Língua Portuguesa: pontos para um balanço. In: Revista Crioula, n. 7, maio, 2010.

Entrevista a João Paulo Borges Coelho. Disponível em http://macua.blogs.com/moambique para_todos/2006/04/joo_paulo_borge.html. Acesso em 30 jan. 2018.

DIAS, Eduardo Costa. Repensar os estudos africanos: descolonizar o pensamento, questionar as práticas, reconfigurar as agendas. In: Revista Lusófona de Estudos Culturais; LusophoneJournalof Cultural Studies, v. 2, n.1, pp. 7-24, 2014.

DIRLIK, Arif. Postcoloniality and History. In: Journal of the Canadian Historical Association, v. 17, n. 2, 2006.

JAUSS, Hans Robert. A história da literatura como provocação à teoria literária. Trad. Sérgio Tellaroli. São Paulo: Ática, 1994.

KAHN, Sheila. Narrativas, rostos e manifestações do pós-colonialismo moçambicano nos romances de João Paulo Borges Coelho. In: Revista Gragoatá, Niterói, n. 24, p. 131-144, 1. sem. 2008. 
KAHN, Sheila; et al. (org). Visitas a Borges Coelho: leituras, diálogos e futuros. Lisboa: Edições Colibri, 2017.

MACAGNO, Lorenzo. Estudos africanos no Brasil: uma questão de afinidades eletivas? In: Revista Tempo, Espaço, Linguagem, v.5, n. 3, set. - dez, 2014.

MELO, Alfredo Cesar. Por um comparativismo do pobre: notas para um programa de estudos. In: Revista Brasileira de Literatura Comparada, n.23, 2013.

MENDONÇA, Fatima. Hibridismo ou estratégias narrativas? Modelos de herói na ficção narrativa de Ngugiwa T'hiongo, Alex La Guma e João Paulo Borges Coelho. In: Via Atlântica, n. $16,2011$.

NESTROVSKI, Arthur. Ironias da modernidade. São Paulo: Ática, 1996.

NOA, Francisco. Modos de fazer mundos na actual ficção moçambicana. In: CHAVES, R.; MACEDO, T. (orgs) Marcas da diferença: as literaturas africanas de língua portuguesa. São Paulo: Alameda Editorial, 2006.

SECCO, Carmem Lúcia T. O corpo moçambicano cindido: história, mito e ficção em As duas sombras do rio, de João Paulo Borges Coelho. In: Revista Via Atlântica, 2009.

SILVA, Ana Claudia. O rio e a casa: imagens do tempo na ficção de Mia Couto [online]. São Paulo: Editora UNESP; São Paulo: Cultura Acadêmica, 2010.

SOARES, Eliane V. Literatura e estruturas de sentimento: fluxos entre Brasil e África. In: Revista Sociedade e Estado, v. 26, n. 2, mai - ago, 2011. 